\title{
Discussion on the Functional Mechanism of the Community Health Service Center in the Existing Medical Service System
}

\author{
Zhi Cheng Niu \\ Qinghe Community Health Service Center, Beijing, China
}

\section{Email address:}

niuzhicheng1857@163.com

\section{To cite this article:}

Zhi Cheng Niu. Discussion on the Functional Mechanism of the Community Health Service Center in the Existing Medical Service System. Science Discovery. Vol. 6, No. 5, 2018, pp. 367-372. doi: 10.11648/j.sd.20180605.19

Received: August 9, 2018; Accepted: September 17, 2018; Published: October 18, 2018

\begin{abstract}
The current situation of patients visiting hospitals is that, large hospitals are overcrowded with patients, but there are relatively insufficient patients in community hospitals. The root cause is that the role of existing basic medical and health institutions has not been properly and fully utilized. If this situation cannot be fundamentally changed, then it is impossible to say that the medical reform has embarked on the road to success. Therefore, if the overall medical development strategy can be implemented to provide more preferential support to the grass-roots hospital, in order to lead the general direction of social and medical development further, and facilitate the work of grass-roots hospitals; the work direction of community health service centers, in terms of business philosophy, examination, treatment, technical means, hospital management, and resource mobilization in all directions etc.., has been adjusted accordingly, so as to create internal conditions and driving factors for more patients to return to the grass-roots hospitals; the large hospitals should also provide more corresponding support and help to community health service centers in the focus of work, with the aim of promoting the development of grass-roots medical institutions objectively at the higher medical level, we believe that the number and categories of diseases of patients visiting basic medical and health institutions will change a lot in the near future, even fundamentally.
\end{abstract}

Keywords: Hospital Visit, Community Health Service Center, Patient Regression

\section{社区卫生服务中心在现有医疗体系当中功能发挥机制探讨}

\section{牛治成}

清河社区卫生服务中心, 北京, 中国

\section{邮箱}

niuzhicheng1857@163.com

\footnotetext{
摘要：目前患者到医院就诊的现状是，大医院就诊的患者人满为患，而社区医院则相对不足，其根本原因是因为现有 的基层医疗卫生机构的作用没有得到应有的、充分的发挥。此种情况如果不能从根本上予以改变, 那就不能说医疗改 革走上了成功之路。因此, 如能使总体医疗发展战略能向基层医院实施更多的倾斜扶持, 以能更多的引领社会及医疗 发展的大方向, 并助力基层医院工作的开展; 社区卫生服务中心的工作方向上, 从经营理念、检查、诊断、治疗、技 术手段、医院管理、以及调动各方面资源, 等等诸多方面, 亦做出适应此种情况的积极调整, 从而为更多的患者回归 基层医院创造内部条件和驱动因素; 大医院的工作侧重点上亦给予社区卫生服务中心以更多的支持和帮助, 从而在上 级医疗层面对基层医疗机构客观上给予助推腾飞作用, 相信不久的将来到基层医疗卫生机构就诊患者的数量及质量会 有很大的改观, 甚至是根本性的变化。
} 
关键词：医院就诊，社区卫生服务中心，患者回归

\section{1. 引言}

目前, 在大城市, 患者到医院就诊的现状是, 大医院 就诊的患者人满为患, 小医院门可罗雀, 使本应在社会健 康医疗保健工作中发挥基础医疗及关键作用的卫生站、卫 生服务中心并未能起到和发挥其应有的重要功能和作用, 尽管, 近一段时间以来, 医疗改革的力度不可谓不大, 包 括: 实施分级诊疗制度; 医药分开; 改善医疗服务质量; 规范医疗服务价格; 医疗机构控费; 财政分类补偿; 医保 支付改革等多项措施 $[1,2]$, 但患者的流向并未发生实质 性变化, 目前的社区卫生服务中心依然主要是保证基本医 疗为功能主体, 辅以一些公共卫生项目为主要目的的医疗 机构存在, 没有真正起到其应有的、全面的社会健康医疗 保健看门人、维护者、守护者的角色作用。因此, 要想根 本改变这种患者就诊流向的“脑体倒挂”的不正常状态，使 社区卫生服务中心真正起到并发挥其应有的作用，在找出 其发生的原因之后, 还必须采取与之配套的、切实可行的、 符合实际的方针策略。首先, 在政策上, 要使总体医疗发 展战略能向基层医院实施更多的扶持倾斜, 从而在社会、 医疗发展的大方向以及保障健康中国战略[3]的实施中, 起 引领和推动作用; 其次, 明确患者到大医院就诊主要诊治 的疾病是: 疑难杂症、需要住院治疗的患者、基层医院转 诊过来的患者、危急重症患者, 其余的, 应该留在方便的 社区卫生服务中心就诊; 再次, 社区卫生服务中心的工作 方向亦应做出适应此种情况的相应调整, 形成较为完善、 高效的基本医疗服务体系[4]。

\section{2. 社区医院患者不足原因分析}

导致目前这种患者就诊流向“脑体倒挂”不正常状态 的原因是:

\section{1. 社区医院无法满足患者需求}

在多数老百姓的心中, 社区卫生机构就是保证基本医 疗，俗话说就是“开药的”。其医疗条件、医疗水平、医疗 技术无法满足患者的需求和要求 [5]。虽然老百姓也深知, 去大医院看病也有些许令人不够满意的因素, 比如说: 由 于患者太多, 某些医务人员的医疗服务态度不够理想; 还 有, 看病几分钟, 而各种排队要几个小时, 有时甚至排了 很长时间的队, 到了窗口却被告知号已挂满, 无号了; 再 有, 去大医院看病的花费不菲, 但由于很多人认为去大医 院就诊, 可以相对放心的去诊治疾病, 并且能够得到自己 相对放心的诊治结果, 所以很多人仍然会涌向大医院看病 就诊。

\section{2. 社区医院医疗设备不足}

社区卫生机构的各种检查手段欠缺、或是根本没有, 致患者不愿意多跑冤枉路。

\section{3．社区医院药品配备不全}

社区卫生机构的各种药品无法满足患者需求, 很多大 医院有的药物, 小医院却没有, 因此还得去大医院取药。

\section{4. 社区医院医务人员缺乏}

社区卫生机构的基层医务人员较为缺乏, 很多医生不 愿意到基层医疗卫生机构工作, 至社区医院无法招到更多 高水平的医生。

\section{5. 社区医院积极主动性不够}

目前, 基层医疗卫生机构仍然以行政命令为主导的完 成工作, 而非主动、积极、创新驱动下的完成, 致一些在 基层可以解决的问题，因怕“麻烦”、或者说“不必要的烦 恼”而不愿意涉足。

\section{6. 政府某些政策配置不够到位}

政府对基层卫生工作的某些政策、法规不够到位, 致 基层医院惧怕发生医疗纠纷, 从而不愿多事, 比如说, 居 家护理、居家养老、居家病床、居家康复等等方面。

\section{3. 社区医院应起到、并发挥的功能作用}

首先, 社区卫生服务中心要能留住 $80 \%-90 \%$ 的小医 院、小诊所可防、可看、可治的常见病、多发病, 并形成 对居民及患者主动的、积极服务; 其次, 社区卫生服务中 心有责任和义务保障辖区居民身体健康, 能够让管片辖区 居民的慢性病的发病率、突发急性病的死亡率逐年下降、 慢性病的管控率逐年提高; 再次, 社区卫生服务中心有责 任和义务照料辖区老、弱、病、残及临终人员 [6], 在成为 政府在老百姓养老、保健以及残疾人照料方面的左膀右臂 的同时, 亦解除了老百姓的后顾之忧, 从而让居民真正放 心、家庭真正放心、社会真正放心。

\section{1. 医、护、防人员是中坚力量}

\subsection{1. 全科医师是核心}

社区卫生服务中心最核心的力量、最核心的资源是全 科医生, 只要他们认真负责、服务好、技术好, 就会在患 者心中永久占据重要的位置, 一有健康医疗方面的问题, 那患者就会首先找他们自己信得过的、服务好的、能让患 者全面了解、理解自己病况、甚至预后及治疗的全科医生。 因此, 发挥全科医生的主观、能动、创造性是社区卫生中 心能否留住病人的关键。

\subsection{2. 中医中药是传统}

充分发挥中医师、中医药人员在社区卫生服务中心的 作用, 并优化中医医疗服务, 要在辖区居民当中普及中医 预防、医疗、保健、健康知识, 大力推广中医、中药传统 
治疗在常见病、多发病以及身体健康、预防、保健方面的 作用, 使百姓、患者在方便的社区医院得到传统医学照料 的同时, 亦使祖国2000多年的传统医学文化深深扎根于基 层社区卫生机构及居民之中, 并使患者从中不断获益。

\subsection{3． 终生照料、服务居民}

对于社区卫生服务中心所管辖区居民, 从其一出生开 始, 医务人员即应给其在社区卫生医疗机构建立终生医疗 档案, 以在其生命的不同阶段予以相应的预防、保健、医 疗等照料, 以及健康宣教等措施 [7], 即, 使每一个人从一 出生就知道有社区卫生服务中心的存在, 也同时把他们的 “心”留在了社区。

\subsection{4. 贴心的预防保健}

在预防保健、疫苗接种方面，社区卫生服务中心的医 务人员应对全辖区的居民实施更加贴心的、亲民的、满意 的服务, 包括, 应用计算机联网制度, 实施到时提醒、错 过补种、入户随访、群体特殊预防接种政策、等等措施。

\subsection{5. 居家患者医护照料}

社区卫生医疗机构的医务人员去患者家庭出诊, 包括: 护理指导、家庭病床的建立、空巢老人的照顾、换药、换导 尿管、家庭病床的输液等, 医疗行政部门应当出台管理条例, 明确指明：出现突发及意外情况而产生的纠纷由谁来承担。 比如说, 肌肉注射、或输液中出现过敏现象; 家庭病床建立 期间、或者技术操作期间突发心梗等急性疾病而致死亡等。 只有解决了这些问题, 行动不便的患者、重病的患者、需要 照顾的患者, 医护人员在社区给予他们医疗照顾时, 才能真 正免除后顾之忧，才能放心大胆的、放开手脚的去工作，社 区卫生服务才能真正跃上一个新台阶。目前情况下，只能是 各社区卫生服务中心自己制定、设计一套服务体系、方针、 策略, 包括居家护理、居家养老、居家病床、居家营养、居 家康复、居家治疗等等方案, 虽也有可操作性, 但须获得上 级医疗行政部门的认可和审批。

\subsection{6. 康复患者照料}

对于康复患者, 社区卫生服务中心应该起到应有的康 复、照料、治疗作用。对于需要康复的病人, 要为他们制 定详细的、切实可行的康复计划, 并在一定时间内监督此 一计划的执行完成。

\section{2. 主动、积极的药品服务}

\subsection{1. 行动不便可送药到家}

老、弱、病、残等行动严重不便、并长期服药的人员， 政策允许范围内, 在社区医院局域网内付费后, 可配送药 物到家。

\subsection{2. 中草药可配送到家}

辖区内的患者, 在社区中医大夫就诊后, 所开具的中 草药可实施药品配送制度, 包括代煎药品。

\subsection{3. 自费药物可配送到家}

自费患者, 在社区医院局域网络医生就诊后, 可给予 实施网上订药、交费后, 药品配送。

\subsection{4. 慢性病药物可配送到家}

对于糖尿病、高血压、冠心病、脑卒中、前列腺增生、 癌症等慢性病长期服药者, 应允许医保患者在社区卫生医 疗机构的局域网内, 医生就诊后, 按照医保规定进行网上 订药, 取药, 直至配送服务。

\subsection{5. 放开药品管制}

应该放开对社区卫生服务中心药品品种的管制, 使之 完全与三甲医院药品品种吻合, 只有这样才能使患者在大 医院就诊之后完全不用再跑回头路, 直接去附近的社区卫 生服务中心、或者社区站取药（至于药品监管则有上级部 门及监察部门, 甚至纪检部门监督执行, 不应以此理由限 制社区医疗机构）。

\section{3. 社区医院的检查、诊断设备}

\subsection{1. 配置各种检查器械}

对较大型的社区卫生服务中心、或者是一定距离内大 医院距离较远、也或附近没有大型仪器诊疗中心的社区卫 生服务中心应该配置各种常规检查仪器, 如检验（尤其是 各种在短时间内可马上出结果的急诊检验项目）、放射、 $B$ 超、CT、核磁、简单急救设备 (如呼吸机) 等, 使患者 可以直接、就近进行检查, 不用再跑大医院, 既方便了病 人, 也留住了病人。如果社区卫生机构暂时不能解决此类 问题, 至少在医联体内, 社区卫生机构的医生应该可以直 接开具三甲医院的各项检查单据, 以使患者在大医院可直 接缴费后检查, 而不是再挂号、看病、再开单。

\subsection{2. 配置诊断兼治疗器械}

社区卫生服务中心应设立并开展一些门诊常规医疗 器械诊断兼治疗项目的检查, 比如: 胃镜、肠镜、乙状结 肠镜、直肠镜、关节镜、膀胱镜、子宫镜等, 在方便社区 居民的同时，也延揽了患者。

\subsection{3. 体检在社区}

只要社区卫生医疗机构各种检查设备及实验室仪器 配置能够满足患者需求, 就应该鼓励将辖区居民的体检放 在社区卫生服务中心, 而不是大医院的体检科, 这样, 每 年居民的体检, 既不用再多跑冤枉路, 也可随时随地进行 检查, 既方便了病人, 又留住了患者, 也让社区医院增加 了收入。

\section{4. 社区医院的治疗}

社区卫生服务中心应重点设立并发展广大患者在常见 病、多发病方面, 方便的、简单的、并行之有效的治疗科室, 比如: 中医的针炎、按摩、水疗、足浴; 理疗科的各种理疗 仪; 口腔科的常规简单治疗; 妇科的人工流产; 外科的小手 术; 简单的美容治疗; 简单的皮肤病器械处理等等。此, 既 让基层医院业务开展的红红火火, 亦留住了病人。 


\section{5. 社区医院的局域网和医联体网}

\subsection{1. 局域网}

辖区内的患者, 在社区医院局域网内, 可实施网上咨 询、网上预约、网上就医、网上会诊等互联网医疗服务。

\subsection{2. 医联体网}

医疗体系内、至少是医院联合体内应该实行计算机联 网互通, 从而确保信息互通、检查结果互用、会诊、教学、 远程医学、指导医疗互达 [8], 以减少患者不必要的跑路, 可达到将患者留在社区医院就诊的目的。

\section{6．社区医院保障辖区居民健康}

\subsection{1. 进驻辖区单位宣教}

社区卫生服务中心的医务人员应对辖区幼儿园、小 学、中学及各个单位进行健康、保健、营养、生活方式疾 病、建立正确的生活方式观念等方面的宣传教育，使他们 从思想上树立正确的生活观、世界观，让一生伴随他们的 是：“按照科学、自然规律生活---这一科学理念”, 同时还 希望每一个人能把这一理念落实于自己的一生行动之中, 由此可以防患于未然---也即不得病、或者少得病, 进而提 高个体、乃至整个民族的健康和寿命。

\subsection{2. 辖区慢病宣教}

社区卫生服务中心的医务人员每月应对辖区居民进 行健康宣传教育一次, 以提高居民对四大慢性病及生活方 式疾病认识率，从而使患者在主动意识上配合医务人员提 高四大慢性病的缓解率、维持率、治愈率, 进而提高居民 生活质量和寿命。

\subsection{3. 普及居民急救演练}

定期对居民，尤其是骨干居民进行突发危急重症疾病 的现场抢救处置的培训、实践及演练, 以提高真实实际情 况发生时的抢救成功率, 进而降低死亡率。

\subsection{4. 家医签约及公共卫生服务}

要使家医团队签约 $90 \%$ 以上覆盖辖区居民, 要使 $100 \%$ 的居民享受政府实施的公共卫生服务，包括慢性病管理、 65岁以上老年人体检、妇女两癌筛查、妇女儿童保健、预 防接种等等多项服务。

\subsection{5. 网络化管理慢病}

全面对辖区患有慢性病的患者集中管理，用信息化、 数字化、网络化达成慢性病的发病率、突发急性病的死亡 率逐年下降、慢性病的管控率逐年提高之目的。

\section{7. 社区医院照料老、弱、病、残及临终人员}

\subsection{1. 社区养老院}

目前我国逐渐进入老龄化社会, 居民的养老日益成 为突出的问题, 尽管政府也想了各种办法, 拿出各种补 贴, 但因为人口基数庞大, 经济状况参差不齐, 距离市 区路程较远等等诸多方面的问题, 导致目前此一问题的
解决仍然离着现实情况以及想要达到的目标距离较远, 因此开辟一种既能够让居民享受到城市社区氛围、又经 济、亲民的养老途径, 不失为一种较理想的办法, 而社 区卫生服务中心作为政府的左膀右臂, 恰好就能承担这 一任务, 达成此一目的。在社区卫生服务中心内开办 养老院, 目前条件下, 应实施一人、或一家两口一间屋, 每间屋、每月收费1500-2000元（具体收费视政府各个 部门的补贴情况而定）, 来去自由, 设置相应的娱乐服 务设施, 由于社区卫生服务中心的医务人员可直接对养 老院的养老人提供医疗、保健服务, 其地理位置距离养 老人的家庭也不远, 又融在社区中, 因此, 其既不失为 一种较理想的养老方式, 也填补了目前养老体系当中的 重要一环。

\subsection{2. 社区临终关怀}

社区卫生服务中心应开办临终关怀病房, 以解除辖 区居民人老之后疾病卧床, 而家中又无人照看, 以及患有 慢性消耗性疾病, 家中亲人又不愿让老人在家中故去的后 顾之忧。

\subsection{3. 社区康复中心}

社区卫生服务中心应开办康复医疗中心。目前每个 社区内有很多需要康复的患者, 不仅包括脑卒中后遗症等 神经系统疾病之后引发的肢体残疾, 还包括先天性脑部疾 病等引发的行动不便, 给家庭及社会带来很多牵挂, 只有 让辖区内需要康复的患者都能得到应有的康复和治疗, 才 能解除家庭、社区、政府的后顾之忧, 而社区卫生服务中 心是政府办的社会机构、又是在社区居民区内的医疗机 构, 恰好可起到此一作用。

\section{4. 社区医院运营机制}

在医疗运营机制上：要让社区卫生中心真正成为“中 心”，上，衔接三甲医院; 下，连接社区站; 而, 社区站 面对广大的居民和患者。

目前的医疗体系下, 大量患者均聚集到大医院, 形 成了“大医院赶集, 小医院冷清”, 未能按照客观规律, 对患者形成“金字塔”似的医疗照顾, 而要恢复这样的正 常关系和架构, 首先要必须明确: 社区卫生服务中心在 目前的医疗体系当中应是真正的医疗中心, 在常规疾病 的诊治处理上, 三甲医院应是辅助并帮助社区卫生服务 中心的功能作用, 包括会诊、出专家门诊等等帮助措施, 只有大病、需要住院的患者、疑难杂症才可以以三甲医 院为主, 但, 正常情况下, 这些患者多数应是从社区卫 生服务中心转诊过来的; 其次, 社区卫生服务中心, 下, 连着社区站, 社区站应该是最“接地气”的医疗机构, 它 们存在于社区内, 离着居民、家庭、患者最近, 既是社 区医生、也是私人医生; 既是解忧医生、也是心理按摩 医生; 既是个体医生、也是家庭医生; 既是医疗、也是 保健; 既是预防疾病的看护者、也是健康教育的宣教者; 既是社区居民健康的守护者、也是族群寿命保证者的重 要一环[9]。 


\section{1. 社区医院患者需求应答调度机构}

社区卫生服务中心应成立一个24小时院办领导下的 应答、调度机构, 对院内院外传来的电话、网络等各种需 求迅速予以回应, 并指挥调度社区卫生中心内相应的人员 执行、完成。

\section{2. 社区医院急救反应体系}

社区卫生服务中心应设立自己的急救车救治体系, 优 化院内及辖区内急诊患者抢救、转诊、运送绿色通道, 并 使医联体内急救通道顺畅、便利化。

\section{3. 社区医院与医联体的联系}

\subsection{1. 专家出诊}

医联体内大医院的专家在社区卫生服务中心内的坐 诊应固定化、常态化，尤其是社区卫生医疗机构所没有的 科室, 专家的坐诊更为重要, 即避免了患者的跑路, 又留 住了病人, 只是初期, 社区卫生中心对专家的宣传和为专 家提前预约更多患者亦为重要一环。

\subsection{2. 社区转诊}

在医联体内, 大医院应预留预约诊疗号源, 对于来自 于社区卫生服务中心的预约患者和预约转诊患者实行优 先就诊、优先检查、优先住院、双向转诊, 以及住院床位、 日间手术预约等优先服务 [10], 社区中心的各个科室要与 医联体内的大医院的各个相应科室之间应建立通信、协 作、合作、联合的工作关系, 以便利相应工作开展。

\subsection{3. 远程互联网}

在医联体内, 大医院所应有的远程会诊、远程影像、 远程超声、远程心电、远程病理、远程查房、远程监护、 远程培训等服务 [11], 应一并提供给社区卫生服务中心以 助社区卫生中心业务的开展。

\section{4. 社区医护人员植根于社区居民}

社区卫生站医护人员应以自己是“居民一分子的心 态”，融入社区居民之中，在向居民及患者提供良好服务 的同时, 以高情商来获得居民发自心底的尊重, 从而为解 决居民和患者医疗及健康方面的问题时, 能互相之间敞开 心扉, 在拉近与患者“心与心之间”的距离的同时, 也为自 己工作的顺利开展奠定良好基础。

\section{5. 社区医院管理}

社区卫生服务中心在管理上要: 符合时代潮流、与时 俱进。现今的时代是人才时代、创新时代、互联网人工智 能时代, 医院的管理必须要跟上时代步伐, 以满足不断增 长的医疗和社会发展需要。

\section{1. 人才是根本}

人才是医院发展的生命线, 留住有能力、有水平的全 科医生, 是社区卫生服务中心发展的必要条件。因此, 留 住人才是社区医院重中之重的方针策略。

\subsection{1. 职工利益}

医院的管理人员应在不损害医院及科室利益的前提 下, 确保每一个职工个人利益的最大化。

\subsection{2. 发展空间}

在遵守医院的各项规章制度及医院要发展这个大前 提下, 医院的管理人员应为医院的每一位工作者提供充分 的发展空间, 包括职称晋升、医院管理、职务晋升等。

\subsection{3. 内在激励}

医院要采取各种激励措施, 从内心激发医务人员奋发 向上、努力工作的主观能动性: 比如, 绩效工资的发放要 在公正、公平、按劳分配, 按劳取酬的同时, 也需要重点 向临床一线、业务骨干、关键岗位以及支援基层和有突出 贡献的人员倾斜, 并合理拉开收入差距; 定期、按时公布 每个人、每个科室的工作量、工作成绩; 奖惩分明, 从而 让每个人不断地看到前途和光明。

\subsection{4. 后勤保障}

医院后勤要充分保证全院医务人员医疗工作的顺利 开展, 包括, 环境、物品供应、医疗器械的维护、保养、 处置全生命周期管理等[12]。

\subsection{5. 解除职工后顾之忧}

医院要尽可能地为医务人员解决后顾之忧, 包括家 庭、孩子入托、上学等。

\section{2. 创新是动力}

如果说良好的管理是医院发展的保证，那么“创新”才 是医院生命力的强大体现, 也是摘取皇冠上的明珠的创举 行为。医院创新的方向, 应该与社区卫生服务中心所从事 的基本工作理念相一致。要在常见病、多发病方面, 要在 方便的、简单的、并行之有效的治疗方面, 要在为患者服 务方面, 要在医院的各项发展建设方面, 采取不断推陈出 新、不断改进、不断有所创造, 在效果上能很快看到诊断、 治疗效果, 在效益上又有安全性以及经济效应的发明创 造。医院应采取各种激励措施, 鼓励各科室创新, 并形成 相互激励、相互争先的良性循环, 对重大、有影响、经济 效益好的创新, 予以重奖, 并广为宣传、传播。

\section{3. 应用新技能、新技术、新业务}

现今的时代, 是互联网、人工智能时代, 医院的发展, 必须充分、有效的利用这一先进的、医院各方面工作必不 可少的、临取新知识、新技能、新方法的工具, 并将其运 用于医院发展的方方面面, 包括信息共享、人工智能、服 务型机器人等等, 让这一承载工具对方便病人就诊、诊断 
治疗, 方便医院医疗及公共卫生工作的开展, 不断地发挥 出划时代、高效的作用。

\section{6. 结论}

要从根本上改变目前大医院就诊患者人满为患, 基层 医院冷冷清清的现状, 必须采取切实可行的、符合实际的 应对措施，尤其是基层社区卫生医疗服务机构。

\section{1. 社区卫生服务中心要起到“中心”作用}

社区卫生服务中心在现有医疗体系当中要能真正起 到医疗“中心”作用，通过经营理念上的、检查上的、诊断 上的、治疗上的、技术手段上的、医院管理上的、以及调 动各方面资源上的, 等等诸多方面的措施, 在达成患者回 归社区卫生服务中心、就诊患者门庭若市之目的的过程中 真正起到、并发挥主要的、且是重要的作用。

\section{2. 大医院对社区医院的支持必不可少}

大医院在此一进程中, 应尽最大可能帮助、支持社区 卫生服务中心，从而在上级医疗层面上、在客观上给予 基层医疗机构助推腾飞作用。

\section{3. 政府对基层医院的政策倾斜起引领推动作用}

政府总体医疗发展战略应能向基层医疗机构实施更 多的政策倾斜扶持, 这样的话, 既能起到更多的引领社会 及医疗发展的大方向的作用, 亦能起到助力基层医院工作 开展之目的, 同时, 亦解除了医务人员的的某些后顾之忧, 为他们更好地完成自己的工作, 增添了更好的砝码。

\section{参考文献}

[1] 2017年3月22日北京市发布《北京市医药分开综合改革实施 方案》。

[2] 2018年3月 20 日国家卫计委《关于巩固破除以药补医成 果持续深化公立医院综合改革的通知》。

[3] 2017年12月22日国家卫计委《基本医疗卫生与健康促 进法 (草案)》。

[4］2017年12月22日北京市《北京市“十三五”期间深化医 药卫生体制改革实施方案》。

[5] 李立强, 王立芬, 朱绯。现阶段社区卫生服务中心的 管理模式探讨, 中华全科医学, 2007,5，（11）: 1004-1005。

[6] 姜志勤, 社区卫生服务站公共卫生服务管理模式实践, 中国保健营养，2017,27（12）。

[7] 李晓光。海拉尔区社区卫生服务中心健康管理模式探 讨，中国初级卫生保健，2015,29（1）：43-44。

[8] 国办发（2017）32号《关于推进医疗联合体建设和发 展的指导意见》。

[9] 郑俊峰, 陈洪波, 朱晓萍, 曹丽芳。社区居民家庭健 康管理模式探讨, 临床医药实践, 2011,20（8）: 638-640。

[10] 国务院办公厅 2015 年9月 11 日《关于推进分级诊疗制度 建设的指导意见》。

[11] 卫生部医疗发展计划《进一步改善医疗服务行动计划 (2018-2020年)》。国卫医发2017（73号）。

[12] 《国务院办公厅关于建立现代医院管理制度的指导意 见》（国办发（2017〕67号）。

[13] 张从新, 彭荣春。社区卫生服务中心管理模式探讨, 中华全科医学，2008．（2）：184-185。 